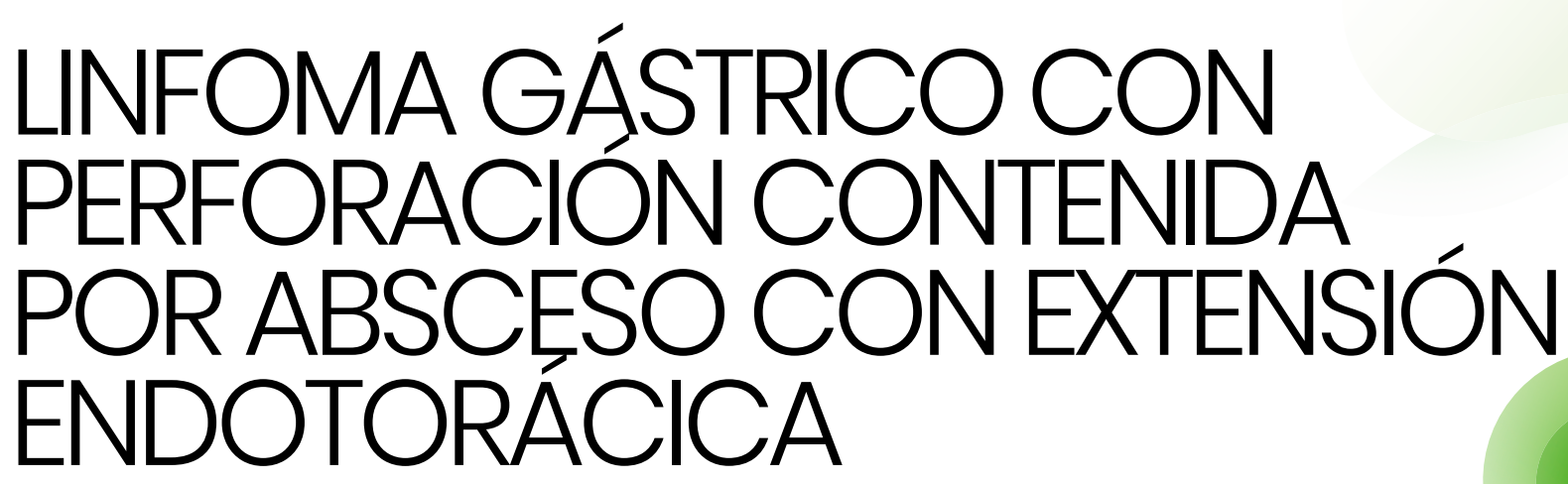

\title{
GASTRIC LYMPHOMA WITH PERFORATION CONTAINED BY AN ABSCESS AND ENDOTHORACIC EXTENSION
}

\section{Díaz Alcázar MM, Martín-Lagos Maldonado A, García Robles A}

Hospital Universitario Clínico San Cecilio. Granada.

Resumen

Mujer de 46 años que consulta por epigastralgia, hematemesis y melenas. Antecedente reciente de consumo de AINES (aintiiflamatorios no esteroideos). Se realiza endoscopia alta objetivando úlcera de aspecto excavado rodeada por pliegues engrosados que parece continuar con una cavidad e impresiona de perforación. Se solicita tomografía computarizada toracoabdominal confirmando la perforación, que está contenida por absceso infradiafragmático con signos de extensión endotorácica. El estudio histológico de las biopsias gástricas concluye linfoma B difuso de células grandes fenotipo no centrogerminal y subtipo inmunoblástico.

\section{CORRESPONDENCIA}

María del Mar Diaz Alcázar

Hospital Universitario Clínico San Cecilio

18016 Granada

mmardiazalcazar@gmail.com

Fecha de envio: 23/06/2021

Fecha de aceptación: 07/09/2021
Los linfomas representan menos del $5 \%$ de los tumores del tracto gastrointestinal, afectando fundamentalmente al estómago. La perforación gástrica ocurre ocasionalmente en pacientes en tratamiento con quimioterapia. Sin embargo, la perforación espontánea es rara, y supone un factor de mal pronóstico además de tener elevada mortalidad.

Palabras clave: linfoma gástrico, perforación gástrica, absceso infradiafragmático.

\section{Abstract}

A 46-year-old woman complains of epigastric pain, hematemesis, and melena. She had a recent history of NSAID (non-steroidal anti-inflammatory drugs) use due to costal pain. Upper digestive endoscopy shows an excavated ulcer surrounded by thickened folds. The ulcer seems to continue with a cavity with fibrin at the edges that impress of perforation. Due to the findings, thoracoabdominal computed tomography is performed. It confirms the perforation, which is contained by an infradiaphragmatic abscess 
with signs of endothoracic extension. Histological study of gastric biopsies concludes diffuse large B-cell lymphoma, immunoblastic subtype.

Lymphomas account for less than $5 \%$ of tumors affecting the gastrointestinal tract, involving mainly the stomach. Gastric perforation sometimes occurs in patients receiving chemotherapy. However, spontaneous perforation is rare and it is a poor prognostic factor with high mortality.

Keywords: Gastric lymphoma, gastric perforation, subphrenic abscess.

\section{Cuerpo}

La perforación gástrica es una complicación típica de úlceras pépticas, sin embargo raramente se asocia con tumores gástricos ${ }^{1}$. Se han descrito pocos casos de perforación gástrica en contexto de linfoma primario gástrico ${ }^{1}$.

Mujer de 46 años sin antecedentes de interés que consulta por epigastralgia, hematemesis y melenas. Antecedente reciente de consumo de AINES (antiiflamatorios no esteroideos) por dolor costal. Se realiza endoscopia digestiva alta urgente objetivando úlcera profunda de aspecto excavado, rodeada por pliegues engrosados y que parece continuar con una cavidad de bordes sucios y fribrinados que impresiona de perforación (Figura 1). Dados los hallazgos se realiza tomografía computarizada toracoabdominal con contraste que confirma perforación de la pared gástrica posterosuperior contenida por la formación de un absceso infradiafragmático de 86x95×75 mm, con burbujas de gas y signos de extensión endotorácica del mismo, ya que no se identifica plano de separación con el diafragma (Figura 2). El estudio histológico de biopsias gástricas concluye linfoma $B$ difuso de células grandes fenotipo no centrogerminal y subtipo inmunoblástico. Se realiza estudio de extensión con PET-TC que objetiva afectación gástrica, ganglionar locorregional y retroperitoneal, esplénica y probablemente pulmonar (Figura 3). Dado que la perforación está

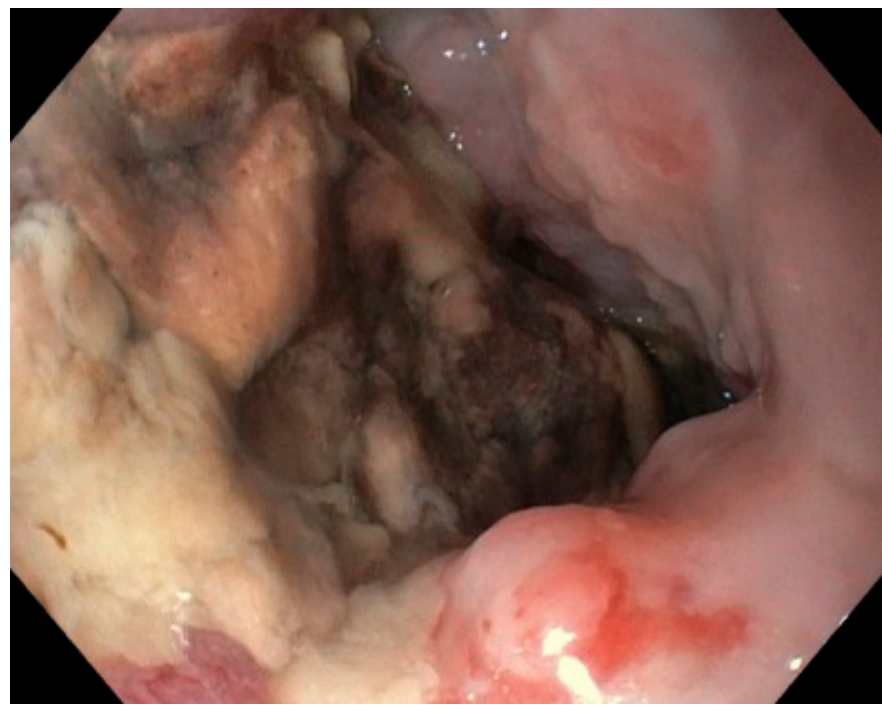

Figura 1

Imagen de endoscopia digestiva alta en que se observa cavidad con bordes sucios y fibrinados sugerente de perforación gástrica.

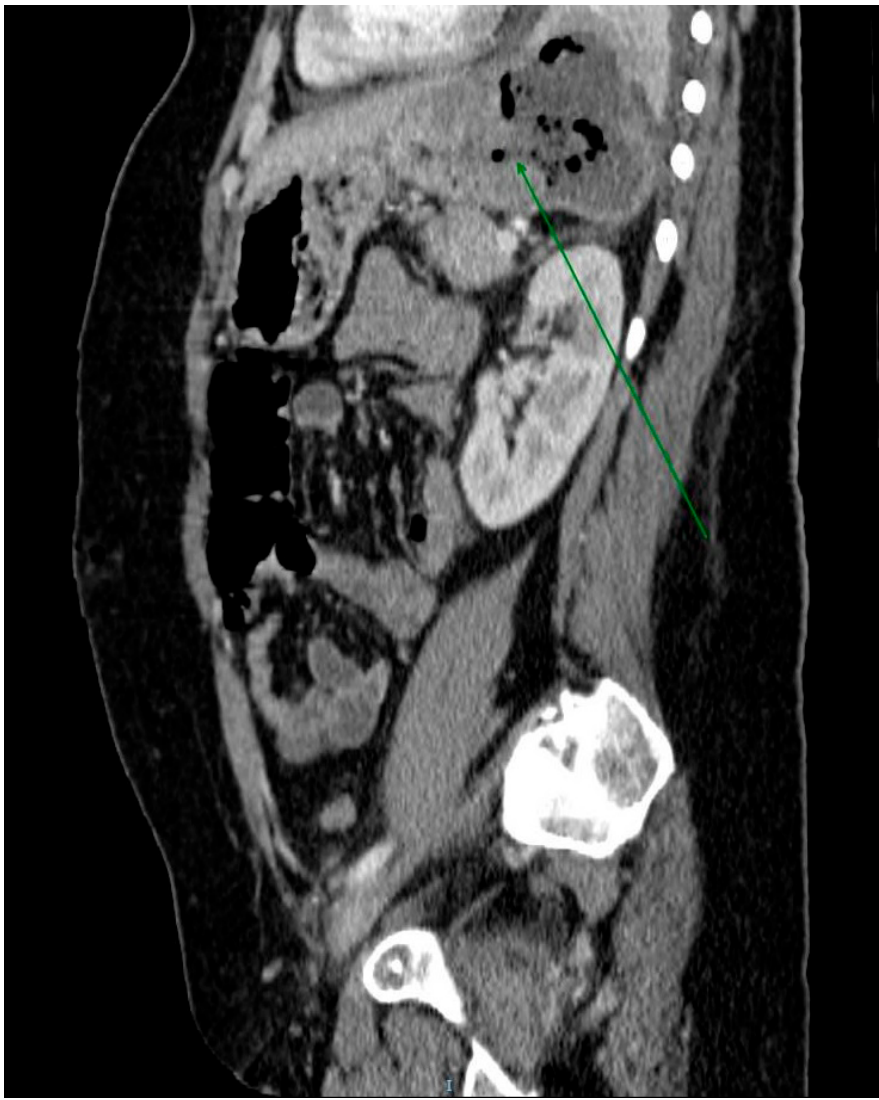

Figura 2

Corte sagital de tomografía computarizada toraco-abdominal con contraste en que se objetiva absceso infradiafragmático con burbujas de gas y signos de extensión endotorácica.

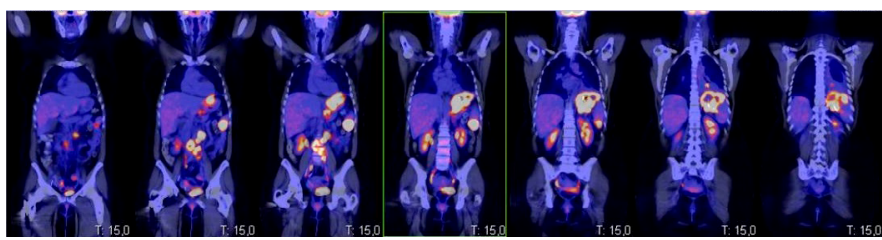

Figura 3

Imagen de PET-TC en que se observa afectación gástrica, ganglionar locorregional y retroperitoneal, esplénica y probablemente pulmonar.

contenida se decide tratamiento conservador. Se realiza drenaje percutáneo de la colección, con aislamiento de Pseudomonas aeruginosa y Streptococus oralis tratados mediante antibioterapia intravenosa. Posteriormente se inicia quimioterapia con régimen CHOP con buena respuesta.

El $40 \%$ de los linfomas no Hodgkin son extranodales, y afectan principalmente al tracto gastrointestinal, aunque representan menos del $5 \%$ de las neoplasias a este nivel ${ }^{1-3}$. El órgano más afectado, como en el caso presentado, es el estómago ${ }^{1,2}$. La mayoría son linfoma T asociado a mucosas (MALT) y linfoma $B$ difuso de células grandes $(\mathrm{DLBCL})^{2,3}$. La clínica suele ser molestias dispépticas inespecíficas, siendo los síntomas $B$ (fiebre, sudoración nocturna y pérdida de peso) 
poco frecuentes, lo que retrasa el diagnóstico ${ }^{1-3}$. La mayoría del los DLBCL suelen diagnosticarse en fases avanzadas ${ }^{3}$.

La perforación gástrica en pacientes con linfoma puede ocurrir ocasionalmente durante el tratamiento con quimioterapia ${ }^{3,4}$. Sin embargo, la perforación espontánea es rara, y supone un factor de mal pronóstico además de tener elevada mortalidad ${ }^{3,4}$. Se debe a que la necrosis tumoral alcanza la subserosa, independientemente de que haya úlcera concomitante ${ }^{2,3}$. La perforación es más frecuente en tumores grandes ulcerados ${ }^{4}$, como el que se describe.

La quimioterapia es el tratamiento de elección, siendo precisa la cirugía en determinadas ocasiones como en presencia de una perforación. En el caso presentado se pudo evitar la cirugía dado que la perforación estaba contenida por la colección infradiafragmática, permitiendo tratamiento conservador.

\section{Bibliografía}

1. Yabuki K, Tamasaki Y, Satoh K, Maekawa T, Matsumoto M. Primary Gastric Lymphoma with spontaneous perforation: report of a case. Sug Today 2000;30:1030-1033.

2. El Asmar A, Khattar F, Alam M, El Rassi Z. Spontaneous perforation of primary gastric B-cell lymphoma of MALT: a case report and literature review. Clin Case Rep 2016;4(11):1049-1052.

3. Ohkura Y, Lee S, Kaji D, Ota Y, Haruta S, Takeji Y, et al. Spontaneous perforation of primary gastric malignant lymphoma: a case report and review of the literature. World J Surg Oncol 2015;13:35.

4. Shimada S, Gen T, Okamoto H. Malignant gastric lymphoma with spontaneous perforation. BMJ Case Rep 2013;17. 